\title{
ESTIMATED POTENTIAL OF ANTONOMASIA IN THE LANGUAGE OF MODERN PRESS
}

\author{
Evgeniya A. Zimina, Julia E. Müller \\ Moscow State Institute of International Relations (University), \\ 76, Prospekt Vernadskogo, Moscow, 119454, Russia
}

\begin{abstract}
The article examines the specific aspects of antonomasia in modern media on the example of online versions of the German-language press: "Süddeutsche Zeitung", "Bild", "Die Zeit". The aim of the study is to identify the pragmatic potential of this type of nomination in the articles on political topics. The relevance of the study is accounted for by contradictory approaches to such a multifaceted linguistic phenomenon as antonomasia within the framework of a pragmatic study of online media discourse. Antonomasia is a means of linguistic nomination, which is realized in speech and performs an evaluative function in the German-language media course, thus causing a special interest of a researcher.

The main objective of the study is to identify the evaluative and influencing functions of antonomasia, which contribute to the formation of a certain position in the reader. The methods of continuous sampling and semantic analysis are used. The selected examples are divided into the cases of antonomasia of the first type (the transfer of a proper name to other politicians) and the second type (the transfer of mythological and literary characters to famous politicians). A special attention is paid to the analysis of the semantic modification of proper names in online media discourse and the background knowledge required for both "decoding" and translation of antonomasia by a native speaker into other languages. The paper states that antonomasia is always based on a secondary nomination and evaluation, it can also be part of the opposition "we" - "they". The analysis of the practical material made it possible to reveal the estimated potential of antonomasia. The authors come to the conclusion that the analyzed material testifies to the relevance of antonomasia in the online media discourse on political topics, and its significant impact on the reader's perception of information.
\end{abstract}

Key Words: antonomasia, metaphor, metonymy, category of estimation, and the language of mass media

For citation: Zimina E.A., Müller J.E. 2021. Sestimated Potential of Antonomasia in the Language of Modern Press. Philological Sciences at MGIMO.Vol. 7. No 1(25). P. 27-36. https://doi. org/10.24833/2410-2423-2021-1-25-27-36

\section{ОЦЕНОЧНЫЙ ПОТЕНЦИАЛ АНТОНОМАЗИИ В ЯЗЫКЕ СОВРЕМЕННОЙ НЕМЕЦКОЯЗЫЧНОЙ ПРЕССЫ}

\author{
Е.А. Зимина, Ю.Э. Мюллер
}


Московский государственный институт международных отношений (университет) МИД России, 119454, Россия, Москва, пр. Вернадского, 76

\begin{abstract}
Аннотация. B статье рассматривается специфика использования антономазии в современных средствах массовой инбормачии на примере онлайн-версий немецкоязычной прессы: „Süddeutsche Zeitung“, „Bild“, „Die Zeit“. Целью исследования является выявление прагматического потенциала данного типа номинации в статьях политической тематики. Актуальность исследования обусловлена неоднозначностью подходов к пониманию такого многогранного языкового явления как антономазия в рамках прагматического аспекта изучения онлайн-медиадискурса. Антономазия является средством языковой номинации, которое реализуется в речи и выполняет в немецкоязычном медиадискурсе оченочную функиию. Основная задача исследования заключалась в выявлении оценочной и воздействующей бункицй антономазии, которые способствуют формированию у читателя определённой позиции по отночению к политическим деятелям, партиям и движениям. Были использованы методы сплошной выборки и семантического анализа, а также приём тингвокультурологического описания. Отобранные примеры были разделень на случаи антономазии первого типа (примеры переноса имени собственного на других политиков) и второго типа (примерь переноса мифологических и литературных персонажей на известных политических деятелей). Особое внимание было уделено анализу семантической модификации имён собственных в онлайн-медиадискурсе и необходимости боновых знаний, отсутствие которых вызывает сложности как «при расшифровке» антономазии носителем языка, так и при переводе подобных наименований на другой язык. В работе отмечается, что антономазия всегда основана на вторичной номинации и несёт в себе оценочную характеристику или может выступать в качестве оппозиции «свой» - «чужой». Анализ практического материала позволил раскрыть оценочный потенииал антономазии. Авторы приходят к выводу, что проанализированный материал свидетельствует о востребованности стилистического приёма антономазии в онлайн-медиадискурсе политической тематики, и оценочный потенциал антономазии оказывает значительное влияние на восприятие читателем информации.
\end{abstract}

Ключевые слова: антономазия, метафора, метонимия, категория оценки, язык онлайн-СМИ

Для цитирования: Зимина Е.А., Мюллер Ю.Э. 2021. Оценочный потенциал антономазии в языке современной немецкоязычной прессы. Филологические науки в МГИМО. Том 7. № 1(25). C. 27-36. https://doi.org/10.24833/2410-2423-2021-1-25-27-36

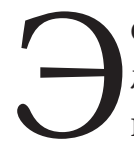

ффективные способы выражения категории оценки на материалах немецкоязычного онлайн медиадискурса и их воздействие на процесс формирования общественного мнения неоднократно становились предметом рассмотрения в новейших исследованиях [7; 8]. Одним из средств выражения оценки является антономазия.

Цель исследования - раскрыть оценочный потенциал антономазии, который должен способствовать формированию у читателя определённой позиции по отношению к политическим деятелям, партиям и движениям.

Материалом для анализа служат онлайн-версии немецкоязычной прессы: „Süddeutsche Zeitung“ [19], „Bild“ [14], „Die Zeit“ [20] за 2016-2019 гг. В данный период в ФРГ разворачивалась предвыборная кампания и прошли выборы в бундестаг (2017), на международной арене важнейшим событием стала победа Д. Трампа на президентских выборах (2016) и начало предвыборной борьбы (2019) в США. Было отобрано 100 статей общим объёмом около 12 п.л., содержащих прецедентные имена, в текстах которых были выявлены случаи использования антономазии.

Актуальность исследования обусловлена тем фактом, что данный тип номинации обладает широким прагматическим потенциалом, в то же время отсутствует единый подход к рассмотре- 
нию антономазии. Отдельные учёные, в частности, И.Р. Гальперин, А.П. Квятковский, Д. Харъюнг [10; 16; 17] рассматривают антономазию как частный случай метонимии, О.С. Ахманова, напротив, считает, что в основе антономазии лежит метафора [2, с. 50]. Однако следует отметить, что основное отличие антономазии как стилистического приёма от метафоры состоит в том, что приём антономазии соотносится с характеристиками и образами конкретного события, лица или места, в то время как при метафоризации происходит отождествление с объектом на основе признаков, общих или характерных для всего класса.

Обратимся к толкованию термина «антономазия» в словаре иностранных слов Duden, который предлагает следующие определения антономазии:

1. Замещение имени собственного наименованием, которое содержит особенные признаки или качества называемого объекта (например, der Zerstörer Karthagos = Scipio; der Korse = Napoleon / разрушитель Карфагена = Сципион; корсиканец = Наполеон) - (здесь и далее перевод авторов статьи).

2. Замещение нарицательного существительного именем собственным, одним из типичных представителей этой группы (например, Krösus = reicher Mann / Крез = богатый человек) [15].

Опираясь на работы отечественных учёных, авторы выделяют следующее определение антономазии А.П. Квятковского: «Антономасия (с греч. «переименование») - вид метонимии, поэтический троп, заключающийся: 1) в замене имени известного лица названием предмета, к нему относящегося, например, ...Или это сказка тупой бессмысленной толпы - и не был убийцею создатель Ватикана? (то есть Микеладжело) (А. Пушкин); 2) в употреблении собственного имени, ставшего нарицательным: Я ускользнул от Эскулапа (то есть от врача), Худой, обритый, но живой (А. Пушкин). Этот троп носит ещё и другое латинское название - прономинация (pronominatio)» [10, с. 44-45].

Следует подчеркнуть, что в настоящее время антономазия рассматривается как сложное и многогранное явление. Так, М.А. Арутюнян определяет антономазию «не просто как стилистический приём, а как процесс и результат номинативной деятельности человека в более широком смысле. Таким образом, явление антономазии изучается не только с точки зрения языка, но и речи» [1]. В своей работе мы основываемся на определении отечественного лингвиста H.M. Наер: «Антономазия - средство языковой номинации, включающее в себя различные виды одновременной реализации предметно-логического и назывного значений, в результате чего объекту присваивается имя, находящееся на пересечении нарицательного и собственного имён, прямо или косвенно указывающее на свойства объекта и таким образом помимо идентифицирующей функции выполняющее информативную функцию» [11, с. 11].

Исследователи К.Р. Каграманов, Н.М. Наер, М.А. Арутюнян, Д. Харъюнг различают антономазию первого типа и антономазию второго типа $[11 ; 1 ; 17]$. Антономазия первого типа строится на переносном использовании имени собственного, при частичном переходе имени собственного в нарицательное, при этом носителя имени собственного, который известен общественности, отличают присущие ему характеристики. Следует отметить, что для понимания антономазии первого типа необходимы фоновые знания, потому что в самом имени собственном, которое используется во вторичной номинации, не заложена положительная или отрицательная оценка. Антономазия второго типа основывается на переносном использовании в функции имени собственного имени нарицательного, оценка при этом может быть выражена в имени объекта напрямую (эксплицитно).

В данной статье рассматривается антономазия первого типа, когда имя собственное, в нашем случае это имя известного политика, используется как основа для номинации группы людей, придерживающихся сходных политических взглядов. Кроме этого, рассматривается антономазия второго типа, когда мифологический или литературный персонаж используется для характеристики той или иной черты характера человека, о котором идёт речь. Данные группы номинаций рассматриваются с точки зрения речи, авторы анализируют реализацию оценочной функции антономазии. Примеры использования антономазии, встречающиеся в политическом медиадискурсе, обладают эмоциональной насыщенностью и служат для формирования у читателя оценочной позиции. 
Антономазия относится к стилистическим приёмам, основывающимся на взаимодействии назывных и предметно-логических значений. Особенно подробно антономазия рассматривалась на материале художественной литературы, в частности на основе такого явления, как «sprechende Namen» (говорящие имена). Проанализированные примеры позволяют сделать вывод о том, что приём антономазии свойственен не только жанру художественной литературы, но и некоторым видам профессионального, в частности медийного дискурса. В нашем исследовании мы рассматриваем антономазию второго типа, то есть «говорящие имена», когда имя собственное, например, Rumpelstilzchen, используется в информационных статьях и комментариях в значении нарицательного существительного. Авторы онлайн-изданий из проанализированных примеров используют это имя для характеристики президента США Дональда Трампа. В этом случае имя нарицательное несёт в себе сильную эмоциональную нагрузку, и в «говорящем имени» лексически выражается отрицательная оценка и отношение автора статьи к известному политическому деятелю. Данный факт свидетельствует о том, что антономазия второго типа обладает оценочным потенциалом.

Рассмотрим более подробно семантическую модификацию имени собственного в политическом медиадискурсе. Здесь можно выделить работы следующих отечественных учёных: именами собственными в немецком газетном дискурсе занималась исследователь Ю.А. Блинова [3], возможности применения антономазии в современных массмедиа с целью привлечения внимания читателя и оценочной функции рассматривает в своей работе А.В. Зеленин [6, с. 57], Е.С. Гончарова исследует влияние концептуальной антономазии в прессе Германии на формирование имиджа бывшего федерального канцлера ФРГ Герхарда Шрёдера [5, с. 94].

Употребление в текстах немецкоязычных онлайн-изданий имён собственных предполагает достаточно лёгкое узнавание и идентификацию реципиентом имени и его носителя, а также основывается не только на лингвистической компетенции, но и на фоновых знаниях читателя. В статье проанализированы примеры, в которых заменяющее слово или словосочетание образовано от имени известного политика или другой известной личности: имя человека (заменяемое) образует пару с производным от имени другого человека или с оборотом речи, включающим такое имя (другого человека). В подобных примерах антономазия строится на переносном значении использования имени собственного, при этом в соответствующем контексте у имени собственного появляется денотативное значение:

Da gibt es die Merz-Freunde, gestützt immer noch von Wolfgang Schäuble, die in den vergangenen Wochen Kritik und Revolte am Wirtschaftsminister und Merkelianer Peter Altmaier schon einmal geübt haben; - Rache dafür, dass der sich im Herbst gegen Merz und für Kramp-Karrenbauer ausgesprochen hatte (SZ, 05.05.2019) [19]. / Там присутствуют «друзья Мерияа, которых по-прежнему поддерживает Вольфаганг Шойбле, критикуюшие в последние недели «сторонника Меркель» министра экономики Петера Альтмайера; - месть за то, что он выступил осенью против Мериа и поддержал КрампКарренбауэр (зд. и далее - перевод авторов).

Перевод на русский язык примеров приводится с целью иллюстрации приёма антономазии. Номинация: П. Альтмайер - заменяющее его сочетание: Merkelianer (сторонник Меркель); или номинация В. Шойбле и заменяющее его слово Merz-Freund (сторонник Мерца). В антономазии первого типа зачастую невозможно определить оценку: Merkelianer - это не положительная характеристика, а способ выражения оппозиции «свой - чужой», тип оппозиции «свой» по принципу принадлежности к действующему федеральному канцлеру Германии Ангеле Меркель, это её последователь. Оппозиция «свой - чужой» является концептуально значимой для онлайн-текстов немецких газет, примеры из которых рассматриваются авторами. «Свой» в нашем контексте это «Merkelianer», то есть поддерживающий политику А. Меркель и придерживающийся схожих политических взглядов. «Чужой» - это, например, в контексте и в оппозиции с «Merkelianer», «Merz-Freunde»- представители и последователи политических идей кандидата на пост председателя ХДС Фридриха Мерца.

В примере ниже представлен один из способов словообразования, когда при целенаправленном изменении грамматических признаков имени собственного, а именно прибавления суффик- 
сов «-ianer», «-ianerin» в определённом контексте образуются номинации с новым предметно-логическим значением. Так, сторонников федерального канцлера Германии А. Меркель называют в онлайн-изданиях Merkelianer oder Merkelianerin / «сторонник или стороннииа Меркель», то есть те, кто поддерживает политику А. Меркель. Вице-канцлера (2005 г.) Франца Мюнтеферинга СМИ называют «Merkelianer», а действующего председателя ХДС «Merkelianerin»:

Wer aber könnte an ihre Stelle treten? Kramp-Karrenbauer ist frische Wahlsiegerin aus dem Frühjahr, sie ist Merkelianerin, also wie ihr Vorbild im Kanzleramt politisch offen, und sie genießt Merkels Gunst (Z, 20.03.2019) [20]. / Но кто же может заступить на её место? Крамп-Карренбауэр - победитель на выборах, состоявшихся весной, стороннииа Меркель, которая, как и её образеи, для подражания в резиденции канилера, политически открыта и пользуется благосклонностью Меркель?

После выбора Аннегрет Крамп-Карренбауэр новым председателем ХДС в СМИ довольно часто используется имя собственное Меркель и производные от этого имени в метафорической и оценочной функции: So glücklich sie über ihren Wahlsieg zu recht sein wird, so dringend nötig wäre es, ein neuerliches Schisma zwischen den Merkelianern und den Merzianern zu verhindern (SZ, 07.12.2018) [19]. / Так счастлива она будет по праву, одержав победу на выборах, так срочно нужно было предотвратить новый раскол между сторонниками Меркель и единомышленниками Мериа. Антономазия в данных примерах обозначает сторонников А. Меркель или Ф. Мерца.

Heute gilt der Schatten der Kanzlerin als Kramp-Karrenbauers größtes Hindernis. Als KrampKarrenbauer in der CDU-Spitze eintraf, suchte man noch gerne die Parallelen zu Merkel: Machtbewusstsein, Verbindlichkeit, Detailwissen, Selbstbehauptung in einer männlich dominierten Partei. Den Eindruck einer besonders engen Beziehung zu Merkel verstärkte die besondere Distanz von Friedrich Merz zur Kanzlerin. Es war Kramp-Karrenbauer selbst, die gegen den Ruf der «Mini-Merkel» anredete. (SZ, 11.06.2019) [19]. I Сегодня тень канилера считается самым большим препятствием для Крамп-Карренбауэр. Когда Крамп-Карренбауэр встала во главе ХДС, её всё ещё сравнивали с Меркель: убеждения, ответственность, важность деталей, самоутверждение в партии, где доминируют мужчины. Впечатление о её особенно тесных отночениях с Меркель ещё больще увеличило расстояние Фридриха Мериа до канилера. Это была сама Крамп-Карренбауэр, которая выступала против репутации «мини-Меркель».

СМИ не случайно называют А. Крамп-Карренбауэр „мини-Меркель“, а немецкие аналитики характеризуют её как кандидата, взгляды которого во многом перекликаются с политикой нынешнего канцлера. Как и Ангела Меркель, Аннегрет Крамп-Карренбауер (сокр. АКК) является представителем крыла партии, которое поддерживает актуальный курс ХДС на более центристскую и либеральную политику, а также открыта к сотрудничеству с другими партнёрами. Имя собственное «Меркель» используется во вторичной (метафорической или метонимической) номинативной функции.

Следует подчеркнуть, все эти новообразования, употребляющиеся в политическом медиадискурсе, связаны со значимой ролью данной личности в жизни страны и ориентированы на носителей языка, которым знакомы конкретные персоналии и актуальные события общественно-политической жизни.

Следующий тип антономазии основывается на коллективной культурной памяти, легендах, библейских и литературных сюжетах. Выразительные и яркие образы создаются путём переосмысления имён персонажей из сказок и мифов. Имя собственное изначально обладает ассоциативным потенциалом, который понимается как «набор стереотипных признаков, свойственных определённому образу в сознании носителей того или иного языка и непосредственно связанных с ним» $[12$, c. 321$]$. Получатели информации связывают знание известных им признаков данного человека с его именем.

\section{Rumpelstilzchen}

Обратимся к толкованию этого понятия в электронном словаре Duden: «Rumpelstilzchen zwergenhafte Gestalt des Volksmärchens, deren erpresserische Macht über ein mit ihrer Hilfe Königin gewordenes Mädchen nur so lange besteht, bis es ihr ihren Namen nennen kann» [15]. / Румпельштильцхен - карлик из народной сказки, который помог девушке стать королевой и обладает над ней 
властью до тех пор, пока она не сможет назвать его имя. В сказке показано, что это злобный, ехидный карлик, легко впадающий в ярость.

Die USA stecken deshalb in einem Dilemma. Für eine Annäherung ist es wenig hilfreich, mit Kritik das Rumpelstilzchen aus Duterte herauszukitzeln. Andererseits ist es für das Ansehen der USA sehr schädlich, wenn Trump keinerlei kritische Worte findet für die Menschrechtsverletzungen, die der philippinische Präsident ohne jeden Zweifel zu verantworten hat. (SZ, 12.11.2017) [19]. / Поэтому перед США дилемма. Сближения сторон не произойдёт, если, используя критику, пытаться изгнать дух злобного карлика из Дутерте. С другой стороны, это очень плохо для репутации США, если Трамп не будет критиковать филиппинского президента за нарушение прав человека, за что он, без всякого сомнения, должен нести ответственность.

По мнению исследователя Л.М. Щетинина, «каждое литературное имя получает стилистическую нагрузку, которая делает более выпуклой и наглядной фигуру наречённого этим именем героя. Реализация стилистической нагрузки имени возможна через его звучание, морфологическое оформление и значение его основы» [13, с. 126-128].

Jetzt rächt sich, dass Seehofers CSU auch dann noch wie ein Rumpelstilzchen gegen Merkels Flüchtlingspolitik gewütet hat, als die Kanzlerin ihren Kurs längst korrigiert hatte. Die CSU hat Merkels Vorgehen als «historischen Fehler» gebrandmarkt (SZ, 25.09.2017) [19]. / Теперь расплачиваются за то, что ХСС под руководством Зеехофера негодовал как злобный карлик из сказки из-за политики приёма беженцев Меркель даже тогда, когда канилер уже давно скорректировала свой курс. ХСС осудил действия Меркель как «историческую ошибку».

Эта антономазия несёт эмоционально-оценочный характер, поскольку подобное сравнение выражает явную иронию. Основанием же для оценки в данном случае являются собственные свойства предметов и явлений, в данном случае характеристики известного персонажа сказки. С семантической точки зрения в основе любой оценки лежит отличие «хорошего» от «плохого», основанное на имплицитном или эксплицитном сравнении.

Один из комментариев в онлайн-издании „Süddeutsche Zeitung“ имеет заголовок «Trump im Rumpelstilzchen-Modus». Речь идёт о действиях и публичном выступлении президента США Д. Трампа в едкой манере известного персонажа из сказки братьев Гримм:

So viel Gegenwind scheint Trump nicht erwartet zu haben. In seiner Rede giftet er gegen alle, die ihn widerlegt haben. «Die sagen, die Kriminalität ist nicht wegen der Mauer gesunken. - Doch, ist sie!» Beweise liefert er dafür nicht. Ein bisschen sieht er in dem Moment aus wie das Rumpelstilzchen, das nicht wahrhaben will, dass die Prinzessin seinen Namen kennt. Im Märchen hat sich das Rumpelstilzchen am Ende - je nach Version - vor Wut selbst entzweigerissen. So weit wird Trump nicht gehen (SZ, 12.02.2019) [19]. / Такого встречного ветра Трамп, похоже, не ожидал. В своём выступлении он ругает всех, кто оспаривает его доводы. «Они говорят, ито преступность упала не из-за стены. - Нет, из-за неё!» Доказательств он не приводит. В тот момент он немного похож на Rumpelstilzchen, которьй не хочет осознать, что принцесса знает его имя. В сказке главный герой в конце - в зависимости от версии сказки - разрывает себя от ярости. Так далеко Трамп не зайдёт.

В приведённых примерах политический лидер США сопоставляется с персонажем известной немецкой сказки. В имени объекта заложена отрицательная оценка, и она выражается эксплицитно. Президента США Д. Трампа онлайн-издание „Süddeutsche Zeitung“ за период 2016-2019 гг. 18 раз называет Rumpelstilzchen. Ассоциативная цепочка приводит читателя к злому гному, герою народной немецкой сказки, который помог девушке и требовал от неё свою награду, он имел власть над ней, пока она не узнала его имени. Сказка заканчивается тем, что злой карлик от ярости разорвал себя пополам. Можно утверждать, что используемые автором газетных новостных статей или комментариев антономазии из примеров выше служат прагматической цели снижения ценности объекта, выражения презрительного отношения к нему. Благодаря ассоциативным связям, включающим в себя важные фоновые знания, интерпретируя имя Rumpelstilzchen, носитель немецкого языка, а также в переводных текстах любой читатель, знакомый со сказками братьев Гримм, может представить себе известного политического деятеля радикальным, импульсивным и отталкивающим от себя человеком. 
В одной из статей используется также приём игры слов, когда президента США Д. Трампа автор называет Трампельштильцхен, когда к имени Rumpelstilzchen прибавляется первая буква фамилии президента - Trumpelstilzchen:

Man muss sich selbst gar nicht zum Trumpelstilzchen aufblasen, um die Dürftigkeit der Darbietung in seiner Rede zur Lage der Nation zu schildern (SZ, 31.01.2018) [19].

Spielt „The Donald“ weiter das Trumpelstilzchen oder hat er uns nur tüchtig in den April geschickt? (B, 15.11.2016) [14].

CSU-Lady Aigner bleibt vornehm: „Falsche Entscheidung!“Journalist Weimar schießt aus allen Rohren: „Trumpelstilzchen! Zappelphilipp! Der erste ADHS-Präsident!“ (B, 31.01.2017) [14]. / Политик ХСС госпожа Айгнер остаётся тактичной: «Неверное решение!» Журналист Ваймар трубит во все трубы: «Трампельштильихен! Цаппельфилипп! Первый СДВГ-президент!»

Следует отметить, что в этих случаях речь скорее идёт не об антономазии, а о другом стилистическом приёме - языковой игре (нем. Sprachspiel): Rumpelstilzchen / Trumpelstilzchen, поэтому мы не будем подробно останавливаться на этом приёме в рамках данного исследования. В последнем примере содержатся кроме новообразованного имени Trumpelstilzchen другие примеры антономазии: имя литературного персонажа Цаппельфилипп, которое означает непоседа или неугомонный Филипп, а также антономазия на основе медицинского термина СДВГ -президент (СДВГ-синдром дефииита внимания с гиперактивностью). В этой статье мы не разбираем подробно имя Цаппельфилипn, так как исследователь Ю.А. Блинова в одной из своих работ тщательно анализирует структуру значения этого имени, а также его связь с литературным источником и функционирование в медийном дискурсе [3]. Отметим лишь, что в нашем случае имя собственное переходит в нарицательное и характеризует нашего героя по манере его поведения, вызывая в памяти целостный образ неугомонного Филиппа. Дополняет образ медицинский термин СДВГ (синдром дефииита внимания и гиперактивности), который подчёркивает заложенную в этой антономазии отрицательную оценку, характеризуя президента страны как очень импульсивного человека.

Антономазия в немецкоязычном политическом медиадискурсе призвана сигнализировать читателю о политико-идеологической позиции газеты. Авторы представляют Дональда Трампа как самого эксцентричного президента США, которого отличает необдуманное и ребяческое поведение, несдержанность и мстительность, он является непредсказуемым холериком, а его непонятные и противоречивые высказывания отражают его умственные способности и рисуют определённый (скорее, негативный) образ у читателя.

Используя имя Rumpelstilzchen и игру слов Trumpelstilzchen, автор вызывает у читателя определённые ассоциации со злым гномом из сказки Я. Гримм и В. Гримм, выражает свою имплицитную оценку и добивается желаемого воздействующего эффекта. Не вызывает сомнения, что антономазия обладает экспрессивной значимостью и позволяет имплицитно дать оценку действиям главы государства, и этот стилистический приём носит пейоративный (отрицательный) характер, поскольку президент представлен с отрицательной стороны. Автор старается подчеркнуть некомпетентность и непредсказуемость главного лидера страны, а употребляемая антономазия несёт в себе оттенок иронии и порицания, указывает на имеющиеся недостатки.

Авторы статей в онлайн-изданиях, используя приём антономазии, достигают поставленной цели: оказывают на адресатов определённое эмоциональное воздействие и могут манипулировать их мнением. При этом восприятие лексического фона антономазии требует от реципиента наличия достаточных фоновых знаний, знания историко-культурных реалий, идиом, Библии, античной мифологии и произведений классиков. Если же узнавания по причине отсутствия фоновых знаний не происходит, то стилистический приём антономазии, а, следовательно, и прагматическое намерение автора статьи оказывается нереализованным, а значение имени предстаёт в зашифрованном виде.

При переводе подобных наименований на другой язык, в частности на русский, возникают сложности, так как различаются политические реалии и структуры языков, способы словообразования, отсутствуют прямые аналоги. При переводе необходимо учитывать системы, нормы и 
стандарты двух языков, а также знания реалий и различия культурных и литературных норм и традиций адресата переводного текста. Так, поисками решения данной переводческой проблемы занимаются С.В. Евтеев, М.А. Чигашева и др. [9; 12].

Исследуя антономазию в современном немецком политическом медиадискурсе, можно прийти к следующему заключению: антономазия строится на приобретении именем собственного денотативного значения. Иными словами, имя собственное частично переходит в имя нарицательное, как с сохранением грамматической формы в результате семантической модификации в контексте, так и с изменением первоначальной грамматической структуры. Другой тип антономазии основан на переносном использовании имени нарицательного, при этом назывное значение возникает в контексте.

Антономазия, имеющая в современной лингвистике статус не просто стилистического приёма, но и процесса и результата номинативной деятельности человека в более широком смысле, репрезентирует эксплицитную или чаще имплицитную форму авторской модальности. В любую эпоху в области средств массовой информации существует необходимое и достаточное количество выделяющихся, запоминающихся имён, которые выполняют оценочную и воздействующую функцию.

Безусловно, употребление в политическом медиадискурсе антономазии как лингвистического приёма обусловлено значимой ролью данной личности в жизни страны и ориентировано на экстралингвистические знания носителей языка, знакомых с конкретными персоналиями и актуальными событиями общественно-политической жизни. Эти политические деятели, сказочные или мифические персонажи хорошо известны целевой аудитории. Поэтому авторы статей, используя антономазию, достигают поставленной цели: оказывают на адресатов определённое эмоциональное воздействие и могут влиять на формирование его мнения в нужном направлении.

Восприятие и выявление иносказательно-дескриптивного компонента антономазии возможно через призму фоновых знаний реципиента, в частности об именах собственных. В этом случае срабатывает и стилистический потенциал антономазии, и заложенное прагматическое намерение автора.

При переводе подобных новообразований на другой язык, в частности на русский, необходимо учитывать системы, нормы и стандарты двух языков, а также знания реалий и различия культурных и литературных норм и традиций адресата переводного текста.

Анализ отобранных примеров наглядно показывает, что антономазия служит для формирования негативного образа современного политика, выявления его отрицательных сторон, для демонстрации злоупотребления своими должностными полномочиями и нарушения общепризнанных норм морали и нравственности.

Как справедливо отмечает немецкий исследователь В. Шульц, «Авторитетные издания освещают политические события, а читатели являются зависимыми от информации, подаваемой в прессе» $[18$, с. 71]. Нельзя не согласиться с М.Н. Володиной в том, что «Современные средства массовой информации информируют человека о состоянии мира, оказывают влияние на весь строй его мышления, на стиль восприятия и тип культуры сегодняшнего дня» [4, с. 10]. Формированию у читателя оценочной позиции способствуют антономазия и прагматическая направленность публицистического стиля. Антономазия представлена не только в художественной литературе, но и, как показывают приведённые примеры, востребована в языке СМИ. Роль оценки, выраженной антономазией, заключается в оказании воздействия на адресата. Рассмотренные примеры антономазии репрезентируют прагматические намерения автора и представляют собой имплицитную форму авторской модальности.

(C) Зимина Е.А., Мюллер Ю.Э., 2021 


\section{Список литературы}

1. Арутюнян М.А. Структура, семантика и прагматика стилистического приема «антономазия» на материалах немецкого языка: Автореф. канд. ...филол. наук. Москва, 2010. 18 с.

2. Ахманова О.С. Словарь лингвистических терминов / О.С. Ахманова. Москва: Советская энциклопедия, 1966. 608 с.

3. Блинова Ю.А. Прецедентные имена собственные в немецком газетном дискурсе: Дис. ... канд. филол. наук. Самара, 2007. $168 \mathrm{c}$.

4. Володина М.Н. «Медийная культура»: Pro et contra (с позиции отечественных и зарубежных исследователей) // Политическая лингвистика. 2018. № 1 (67). С. 10-18.

5. Гончарова Е.С. Роль концептуальной антономазии в формировании имиджа Г. Шредера // Филологические науки. Вопросы теории и практики. 2016. № 12-4. С. 94-97.

6. Зеленин А.В. Антономазия в языке современной прессы // Русский язык в школе. 2015. № 9. С. 57-64.

7. Зимина Е.А. Лексические способы реализации категории оценки в немецкоязычном газетном дискурсе // Филологические науки в МГИМО. 2019. Том 17. № 1. С. 19-25.

8. Зимина Е.А. Оценочные стратегии информационных статей и комментариев в немецкоязычном газетном дискурсе: Автореф. канд. ...филол. наук. Москва, 2005. 18 с.

9. Евтеев С.В. Перевод: эквивалентно - насколько возможно, и адекватно - насколько нужно // Вестник Брянского государственного университета. 2017. № 1 (31). С. 262-267.

10. Квятковский А.П. Поэтический словарь. Москва: Советская энциклопедия, 1966. 375 с.

11. Наер Н.М. Структура, семантика и прагматика антономазии (на материале немецкого языка). Москва: Прометей, 2011. 142 c.

12. Чигашева М.А. Ассоциативный потенциал антропонимов в немецком и русском языке // Вестник Брянского государственного университета. 2015. № 2. С. 319-323.

13. Щетинин Л.М. Слова, имена, вещи. Ростов-на-Дону: Издательство Ростовского университета, 1966. 222 с.

14. Bild (B) [Электронный ресурc]. URL: https://www.bild.de (Дата обращения 27.04.2020).

15. Duden Online. Wörterbuch. Bibliographisches Institut GmbH. [Электронный pecypc]. URL: https://www.duden.de/ rechtschreibung (Дата обращения 16.03.2020).

16. Galperin I.R. Stylistics / I.R. Galperin. Moscow: Vysshaia Shkola, 1981. 334 S.

17. Harjung Dominik. Lexikon der Sprachkunst. Die rhetorischen Stilformen. Mit über 1000 Beispielen. München, Verlag C.H. Beck, 2000.

18. Schulz W. Wirkungen der Massenmedien. Ergebnisse und Erklärungen / W. Schulz // Politische Bildung, 1988. № 21. S. 59-74.

19. Süddeutsche Zeitung (SZ) [Электронный pecypc]. URL: https://www.sueddeutsche.de (Дата обращения: 30.08.2019).

20. Zeit (Z) [Электронный pecypc]. URL: https://www.zeit.de/index (Дата обращения: 18.10.2019).

\section{References}

1. Arutiunian, M.A. Struktura, semantika i pragmatika stilisticheskogo priema «antonomaziia» na materialakh nemetskogo iazyka: Avtoref. kand. ...filol. nauk. [The structure, semantics and pragmatics of the stylistic device «antonomazia» based on the materials of the German language]. Kand. filol. nauk. Avtoref. Moscow, 2010. 18 p.

2. Akhmanova, O.S. Slovar' lingvisticheskikh terminov [Dictionary of linguistic terms]/ O.S. Akhmanova. Moscow: Sovetskaia entsiklopediia, 1966. $608 \mathrm{p}$.

3. Blinova, Iu.A. Pretsedentnye imena sobstvennye v nemetskom gazetnom diskurse: Dis. ... kand. filol. nauk. [Precedent proper names in German newspaper discourse]. Kand. filol. nauk. Diss. Samara, 2007. 168 p.

4. Volodina, M.N. «Mediinaia kul'tura»: Pro et contra (s pozitsii otechestvennykh i zarubezhnykh issledovatelei) [«Media culture»: Pro et contra (from the perspective of domestic and foreign researchers)] // Politicheskaia lingvistika. 2018. № 1 (67). pp. 10-18.

5. Goncharova, E.S. Rol' kontseptual'noi antonomazii v formirovanii imidzha G. Shredera [The role of conceptual antonomazia in the formation of G. Schroder’s image] // Filologicheskie nauki. Voprosy teorii i praktiki. 2016. № 12-4. pp. 94-97.

6. Zelenin, A.V. Antonomaziia v iazyke sovremennoi pressy [Antonomazia in the language of the modern press] // Russkii iazyk $v$ shkole. 2015. № 9. pp. 57-64.

7. Zimina, E.A. Leksicheskie sposoby realizatsii kategorii otsenki v nemetskoiazychnom gazetnom diskurse [Lexical methods of implementation of the evaluation categories in the german newspaper discourse] // Filologicheskie nauki v MGIMO. 2019. Tom 17. № 1. pp. 19-25.

8. Zimina, E.A. Otsenochnye strategii informatsionnykh statei i kommentariev v nemetskoiazychnom gazetnom diskurse: Avtoref. kand. ... filol. nauk. [Evaluation strategies for news articles and commentaries in german-language newspaper discourse]. Kand. filol. nauk. Avtoref. Moscow, 2005. 18 p.

9. Evteev, S.V. Perevod: ekvivalentno - naskol'ko vozmozhno, i adekvatno - naskol'ko nuzhno [Translation: equivalent - as far as possible, and adequate - as needed] // Vestnik Brianskogo gosudarstvennogo universiteta. 2017. № 1 (31). pp. 262-267.

10. Kviatkovskii, A.P. Poeticheskii slovar'. [Poetic dictionary] Moskva: Sovetskaia entsiklopediia, 1966. 375 p.

11. Naer, N.M. Struktura, semantika i pragmatika, 2011. 142 p. antonomazii (na materiale nemetskogo iazyka). [The structure, semantics and pragmatics of antonomazy (based on the German language)] Moscow: Prometei, 2011. 142 p.

12. Chigasheva, M Assotsiativnyi potentsial antroponimov v nemetskom i russkom iazyke [Associated potential of anthroponyms in German and Russian] // Vestnik Brianskogo gosudarstvennogo universiteta. 2015. № 2. P. 319-323. 
13. Shchetinin, L.M. Slova, imena, veshchi. [Words, names, things] Rostov-na-Donu: Izdatel'stvo Rostovskogo universiteta, 1966. $222 \mathrm{p}$.

14. Bild (B), www.bild.de (Accessed 27 April 2020).

15. Duden Online. Wörterbuch. Bibliographisches Institut GmbH, www.duden.de/rechtschreibung (Accessed 16 March 2020).

16. Galperin, I.R. Stylistics / I.R. Galperin. Moscow: Vyshsaia Skola, 1981. 334 p.

17. Harjung, Dominik. Lexikon der Sprachkunst. Die rhetorischen Stilformen. Mit über 1000 Beispielen. München, Verlag C.H. Beck, 2000.

18. Schulz, W. Wirkungen der Massenmedien. Ergebnisse und Erklärungen / W. Schulz // Politische Bildung, 1988. № 21. pp. 5974.

19. Süddeutsche Zeitung (SZ), www.sueddeutsche.de (Accessed 30 August 2019).

20. Zeit (Z), www.zeit.de/index (Accessed 18 October 2019).

\section{Сведения об авторах:}

Зимина Евгения Александровна - кандидат филологических наук, доцент кафедры немецкого языка МГИМО (Россия, Москва). Сфера научных и профессиональных интересов: лексикология немецкого языка; политический медиадискурс; ИКТ; проектная работа. E-mail: e.a.zimina@my.mgimo.ru

Мюллер Юлия Эдуардовна - кандидат филологических наук, доцент, доцент кафедры немецкого языка МГИМО (Россия, Москва). Сфера научных и профессиональных интересов: сравнительно-историческое, типологическое и сопоставительное языкознание, терминология, онлайн курсы немецкого языка. E-mail: j.mueller@my.mgimo.ru

\section{About the authors:}

Zimina Evgeniya Alexandrovna - PhD, Associate Professor of German Language Department MGIMOUniversity (Russia, Moscow). Spheres of research and professional interest: lexicology of the German language; newspaper discourse; ICT. E-mail: e.a.zimina@my.mgimo.ru

Müller Julia Eduardovna - PhD, Associate Professor of German Language Department MGIMO-University (Russia, Moscow). Spheres of research and professional interest: comparative historical, typological and comparative linguistics, terminology, online German courses. E-mail: j.mueller@my.mgimo.ru 